Editorial

\title{
The Law Changes Behaviors: Is It Just Enough?
}

\section{Dae Ho Lee}

Department of Oncology, Asan Medical Center, University of Ulsan College of Medicine, Seoul, Korea

The "Act on Hospice and Palliative Care and Decisions on Life-Sustaining Treatment for Patients at the End of Life" has come into effect in Korea since 2018, primarily aiming at the maintenance of the patients' dignity and value as human beings by assuring the best interests of the patients towards the end of life and by respecting their self-determination. According to the law, the patients or their family, as appropriate surrogate decision-makers, can express their preferences on life-sustaining treatment (LST) or request their doctor(s)-in-charge to prepare a LST plan by using the official documents. On the other hand, the law requires doctor(s)-in-charge to provide the relevant information of the preparing the LST plan and to obtain the confirmation from the patients on whether they understand the LST plan [1].

Kim et al. [2] reported in the journal that only $13 \%$ of decedents with cancer used the legal forms to express their preference and made their own decision regarding their LST, while a LST plan was prepared by family members in $12 \%$, and it was not built officially in the other 75\%. I don't think that the non-compliance to the law is equal to the system failure. However, it means the law has much room for improvement and successful settlements. Regarding this, the characteristics of the decedents who complied to the law were noteworthy in that those who expressed their preferences were younger, more frequently lived in a city, had more comorbidities, or suffered longer from cancer. Those who made self-determination utilized hospice facilities more frequently and did intensive care units (ICU) less frequently. However, there still remains a possibility, regardless of whether the act is in effect or not, that those with the above listed are more likely to express their preference. Actually, I am not sure which one contributed more in relation to the non-compliance to the law: the lack of patients' understanding on their disease status or the lack of understanding on the law. Regarding this, Lee et al. [3] showed that cancer the patients were much more likely to make the LST decision than the non-cancer patients, suggesting that understanding of their disease might be important in self-determination. Therefore, the evidence that the patient's interest and self-determination is ensured and enforced by the act itself is needed. On the other hand, some concerns are also raised. Unexpectedly, those who belonged to the highest income quintile was less likely to express their preferences, suggesting that the act might not ensure the patient's best interest. Compared to those who made self-determination, those with family-determination utilized hospice care units more frequently and ICUs less frequently, suggesting as well that there might exist conflict of the best interest between the patient and family. Further researches should be done to evaluate whether the act ensures the patients' best interest and assists the patients' decision for their end-of-life plan.

Of note, Won et al. [4] reported that there was no difference in terms of the use of LST and ICU before and after the enforcement of the law, although there was difference in terms of the use of hospice care unit. Was it just time lag between the law coming into 'effect' and 'effectiveness'? What if the law did not work well in the real world? We have to rethink about not only the purposes of the law but also the expected outcomes. The reduction of use of LST and/ or ICU was not the only or main purpose of the law. However, it should be regarded as one of the most important outcomes when evaluating both positive and negative effects of the act. In a sense, we need to define more specifically or specify not only what but also when and where LST and ICU care is or becomes 'unnecessary' to help all stakeholders to better understand and execute the law. In this regard, Baek et al. [5] showed an interesting and informative finding that the patients completed the 6 forms mandated by the act when they were close to death. The mean time between completing a form of 'life-sustaining treatment plan' and filling out a form of "implementation of life-sustaining treatment" was only 8.6 days. It might not be enough for the patients, family members, and treating doctors to reach the consensus of 'unnecessariness.'

The law can be a powerful tool to make a change in the society, but it also places the limits on what we can do. We should be prepared to wrestle against the difficulties with respects to the social and ethical concerns as well as the legal ones, not only before making a law, but also even after the enactment of the law, keeping in mind that the road to the hell is paved with the good intentions and the devil is in the details. On the contrary, the god is also in the details.

Correspondence: Dae Ho Lee

Department of Oncology, Asan Medical Center, University of Ulsan College of Medicine, 88 Olympic-ro 43-gil, Songpa-gu, Seoul 05505, Korea

Tel: 82-2-3010-3214 Fax: 82-2-3010-6961 E-mail: leedaeho@amc.seoul.kr

Received September 13, 2021 Accepted September 14, 2021 Published Online September 23, 2021 


\section{References}

1. Korean Law Information Center. Act on decisions on life-sustaining treatment for patients in hospice and palliative care or at the end of life [Internet]. Sejong: Korea Ministry of Government; 2017 [cited 2021 Sep 1]. Available from: https://law.go.kr/LSW/1sInfoP.do?lsi Seq=180823\&viewCls=engLsInfoR\&urlMode=engLsInfoR\#000.

2. Kim HJ, Kim YJ, Kwon JH, Won YW, Lee HY, Baek SK, et al. Current status and cardinal features of patient autonomy after enactment of the Life-Sustaining Treatment Decisions Act in Korea. Cancer Res Treat. 2021;53:917-25.

3. Lee HY, Kim HJ, Kwon JH, Baek SK, Won YW, Kim YJ, et al. The situation of life-sustaining treatment one year after enforcement of the Act on Decisions on Life-Sustaining Treatment for Patients at the End-of-Life in Korea: Data of National Agency for Management of Life-Sustaining Treatment. Cancer Res Treat. 2021;53:897-907.

4. Won YW, Kim HJ, Kwon JH, Lee HY, Baek SK, Kim YJ, et al. Life-sustaining treatment states in Korean cancer patients after enforcement of Act on Decisions on Life-Sustaining Treatment for Patients at the End of Life. Cancer Res Treat. 2021;53:908-16.

5. Baek SK, Kim HJ, Kwon JH, Lee HY, Won YW, Kim YJ, et al. Preparation and practice of the necessary documents in hospital for the "Act on Decision of Life-Sustaining Treatment for Patients at the End-of-Life". Cancer Res Treat. 2021;53:926-34. 